\title{
Trabalho e produtivismo: saúde e modo de vida de docentes de instituições públicas de Ensino Superior
}

\author{
Izabel Cristina Ferreira Borsoi ${ }^{1}$ \\ Universidade Federal do Espírito Santo (Vitória, ES)
}

\begin{abstract}
Este artigo tem por objetivo discutir a intensificação do trabalho e suas implicações no modo de vida e na saúde de docentes do ensino público superior. Ele teve como base pesquisa realizada em uma universidade pública federal e aborda condições e jornada de trabalho, formas de organização e de efetivação de atividades docentes, além de sentimentos e modos de sofrimento e adoecimento indicados por 96 professores efetivos (56 homens e 40 mulheres), vinculados ou não a programas de pós-graduação. Os resultados apontam que a maioria qualifica seu trabalho como precário, sobretudo quanto à infraestrutura material; julga trabalhar sob forte exigência de atingir metas de produtividade - esta considerada fundamentalmente como sendo a publicação; e estende a jornada para o espaço doméstico. Parte significativa dos entrevistados apresenta queixas quanto à sua saúde, sendo predominantes aquelas de ordem psicoemocional e/ou psicossomática. A maioria dos casos de adoecimento é desconhecida pela administração universitária.
\end{abstract}

Palavras-chave: Intensificação do trabalho docente, Saúde, Modo de vida, Produtividade, Precariedade.

Labor and productivism: health and lifestyle of professors at public Higher Education institutions

This paper aims at discussing the intensification of work and its implication to the lifestyle and health of professors in the public higher education. It was based on a research carried out at a Brazilian federal public university and it approaches work conditions and workday, forms of organizing and accomplishing the teaching activities, as well as feelings and ways of suffering and sickening indicated by 96 effective professors (56 men and 40 women), working in graduate programs or not. The results point out that most of them regard their job as precarious, above all in terms of material infrastructure; they believe to work under a high pressure to reach productivity goals - the latter mostly referring to publication; and they extend their workday to household. A significant part of respondents complains about their health, predominantly with regard to psycho-emotional and psychosomatic issues. Most sickening cases are unknown by the university administration.

Keywords: Intensification of teaching work, Health, Lifestyle, Productivity, Precariousness.

\section{Introdução}

$\mathrm{D}$ esde a década de 1990, o governo federal vem criando medidas que visam redefinir o aparelho estatal, principalmente na área administrativa, âmbito no qual se situam os projetos de reforma da educação superior. As ideias centrais norteadoras dessa reforma são "a modernização ou o aumento de eficiência" da administração pública, o que pode ser traduzido por "flexibilidade e redução de custos" (Sguissardi \& Silva Junior, 2000). As ações adotadas durante esse período vêm oferecendo elementos para o surgimento de uma nova cultura universitária, centrada em uma lógica mercantil que tende a transformar as universidades em prestadoras de serviços para o mercado (Silva Junior, 2005; Sguissardi \& Silva Junior, 2009).

Essa reestruturação universitária tem como parâmetro o conjunto de transformações que ocorre no mundo do trabalho, em âmbito global, desde a década de 1970, e cujos desdobramentos têm sido os mais amplos e diversos. A precarização do trabalho e as crescentes

1 Psicóloga. Doutora em Sociologia. Professora do Departamento de Ciências Sociais e do Programa de Pós-Graduação em Ciências Sociais da Universidade Federal do Espírito Santo. 
exigências de metas, qualidade e excelência produtivas são aspectos que compõem esse panorama do mundo laboral. Aqui, a noção de precarização está relacionada ao processo de reestruturação produtiva, que trouxe em seu seio formas de flexibilização dos vínculos empregatícios, das relações de trabalho, da jornada e das condições de trabalho etc. Diz respeito, portanto, às expressões contemporâneas do trabalho precário, sendo este último uma característica inerente ao capitalismo (Borsoi, 2011).

Nesse cenário, é perceptível que os trabalhadores dos setores de atividades produtivas ou de serviços estão submetidos a alguma forma de precarização da situação de trabalho. A intensidade disso parece ser maior ou menor, dependendo da modalidade do vínculo de trabalho - se público ou privado, se terceirizado ou não terceirizado, se formal ou informal - e, em alguma medida, da capacidade de mobilização dos trabalhadores e do seu nível de qualificação.

Muitas vezes, mesmo a existência de vínculos formais e o elevado grau de qualificação de algumas categorias profissionais não têm sido suficientes para proteger os trabalhadores da condição precarizada em determinados setores ou atividades - como pode ser notado na maioria das instituições públicas de Ensino Superior, atingindo uma categoria até então aparentemente protegida, dadas as características específicas de suas atividades.

Este artigo tem por objetivo discutir a intensificação do trabalho e suas implicações no modo de vida e na saúde dos docentes, tomando como base uma pesquisa realizada na Universidade Federal do Espírito Santo (Ufes), localizada na região Sudeste ${ }^{2}$. O ponto de partida é a constatação de que a reestruturação universitária não tem contemplado mudanças efetivas das condições laborais e tem, sobretudo, resultado em intensificação do trabalho docente, uma vez que o aumento do contingente de docentes não se dá na mesma proporção em que se expandem as demandas de trabalho.

No que diz respeito à intensificação do trabalho nas universidades federais, Sguissardi e Silva Junior (2009), tomando como referência sete instituições da região Sudeste, apontam que, entre 1995 e 2005, houve um crescimento vertiginoso do número de cursos de graduação e de programas de pós-graduação e, por consequência, do número de alunos. Obviamente, esse crescimento foi maior ou menor dependendo do nível de desenvolvimento e relevância da universidade. Tomando como parâmetro as duas universidades localizadas nos extremos dessa expansão, a que menos cresceu foi a Universidade Federal Paulista (Unifesp) e a que mais se expandiu foi a Ufes, alvo da pesquisa que fundamenta este artigo.

Nesse caso, de acordo com os autores mencionados, nesse intervalo de 10 anos, a Ufes saltou de 42 cursos de graduação para 47 (um aumento de 11,9\%), de 9 cursos de mestrado para 19 (um aumento de 111,1\%) e de 1 curso de doutorado para 5 (um aumento de 400\%), segundo Sguissardi e Silva Junior (2009).

A mesma expansão não se verifica na Ufes em relação ao corpo docente no período em questão. Entre 1995 e 2005 houve um aumento de 33\% no número de professores, saltando de 896 para 1.190 (Sguissardi \& Silva Junior, 2009). Em meados de 2010 havia, aproximadamente, 1.200 professores $^{3}$, um crescimento de meros $0,8 \%$ nos últimos cinco anos, período em que houve maior expansão em termos de cursos e número de matrículas.

Essas informações apontam um aspecto importante que envolve as universidades federais de modo geral: em maior ou menor grau, houve elevação significativa (e, muitas vezes, brutal) da demanda de trabalho docente e um acréscimo insignificante no corpo docente efetivo, exatamente aquele que assume as incumbências da pós-graduação, tendo, por isso, a obrigatoriedade de manter elevada a denominada "produção científica".

\footnotetext{
2 Embora trate-se de uma pesquisa acadêmica, cujo projeto não tem relação com demanda prévia de qualquer instituição, ela teve apoio da associação de docentes da Ufes no que toca ao custeio de material e à assessoria de terceiros.

3 Informações obtidas no site oficial da Ufes em junho de 2010.
} 
A imposição de parâmetros de produtividade e a enorme diversidade de atividades transitam entre as exigências de investimento intelectual propriamente dito - traduzidas em aulas, pesquisa, relatórios científicos, artigos, livros etc. - e as exigências de cunho burocrático, as reuniões de trabalho em horário de almoço, a leitura de e-mails e a respectiva resposta a eles etc. (Lopes, 2006). O trabalho docente tem natureza tal, que permite que: seja realizado, em parte, fora do ambiente institucional; extrapole amiúde os limites específicos da jornada regimental contratada; não possibilite visibilidade clara de seu produto; dependa, em grande medida, de condições especiais para ser efetivado - a exemplo da preparação de aulas e da elaboração de textos científicos, artigos etc.; haja, por parte do professor, relativo controle sobre suas atividades, bem como sobre a entrada e saída da instituição.

Características como essas contribuíram, de certa maneira, para que o docente não se percebesse como um trabalhador "típico" ${ }^{4}$ ou passasse a se ver como um "não trabalhador". Essas percepções começaram a se modificar quando as instituições públicas tiveram que adotar princípios e critérios de gestão do trabalho semelhantes aos do modo de organização do setor privado: política produtivista, estímulo à competição, exigência crescente de maior qualificação profissional etc.

O problema é que a atividade docente realiza-se na dimensão imaterial do trabalho por excelência ${ }^{5}$. Assim, os princípios e critérios referidos no parágrafo anterior impactam de modo avassalador tanto a qualidade da produção acadêmica - que passa a ter como parâmetro principal a quantidade - quanto a saúde e o modo de viver dos docentes. Um modo de viver que já não reconhece os limites entre o tempo de trabalho e o de não trabalho.

\section{Percurso metodológico}

A pesquisa foi realizada entre outubro de 2009 e março de 2010 e envolveu 96 docentes efetivos de um universo de $403^{6}$. São 56 homens (58,3\%) e 40 mulheres $(41,7 \%) \mathrm{com}$ idade média de 46,7 anos, variando entre 26 e 68 anos, distribuídos por 18 departamentos acadêmicos. Majoritariamente, os professores se declararam casados ou em união estável, com filhos e tendo residência própria, já quitada ou financiada.

Os departamentos aos quais estão vinculados foram selecionados considerando-se a existência de programas de pós-graduação em funcionamento por, ao menos, três anos garantindo, assim, o triênio para uma primeira avaliação por parte da Coordenação de Aperfeiçoamento de Pessoal de Nível Superior (Capes) - e integram diferentes centros ${ }^{7}$ : Tecnológico, de Educação, de Ciências Humanas e Naturais, de Ciências Jurídicas e Econômicas, de Ciências Exatas e de Ciências da Saúde. Assim, foi contemplada uma grande diversidade de áreas do conhecimento.

Os docentes foram convidados, através de reuniões departamentais e de e-mails, a responder um conjunto de perguntas, fechadas e abertas, que constavam em um instrumento denominado "Protocolo de estudo sobre trabalho docente" (PETD), desenvolvido

\footnotetext{
4 A expressão "trabalhador 'típico"” é adotada aqui para se referir a quem trabalha nos setores privados da indústria, do comércio ou dos serviços e não realiza trabalho imaterial nos moldes da atividade acadêmica.

5 A expressão "trabalho imaterial" diz respeito à presença de uma maior dimensão intelectual nas atividades laborais nas grandes empresas e no setor de serviços, e "expressa a vigência da esfera informacional da forma mercadoria [...]" (Antunes, 2006, p. 36).

6 A relação entre o universo de 403 docentes efetivos e a amostra de 96 participantes apresenta uma margem de confiança de $95 \%$, com erro amostral de $8,7 \%$, considerado acima do usual, que é de 5\%. É preciso considerar, entretanto, que os resultados desta pesquisa dependeram da adesão dos professores, o que impossibilitou a construção de uma amostragem aleatória, que, por óbvio, seria estatisticamente mais representativa do universo pesquisado.

7 Esses centros se configuram como instâncias acadêmico-administrativas às quais se vinculam conjuntos de departamentos. Os departamentos que compõem cada centro mantêm, na maioria das vezes, afinidades em termos de áreas de conhecimento.
} 
especificamente para esse fim. Ele foi apresentado em versão impressa e on-line, ficando a critério do docente escolher de que forma gostaria de participar da pesquisa. Em ambas as versões ficou resguardada a identidade do participante ${ }^{8}$.

O protocolo abordou: jornada e condições de trabalho; forma de organização das atividades de ensino, pesquisa e extensão; sentimentos em relação ao trabalho; aspectos relativos à saúde e ao modo de organização do tempo liberado do trabalho; e impressões gerais sobre a própria atuação como docente, sobre a universidade e sobre as perspectivas quanto ao futuro?.

Os resultados oriundos das respostas às perguntas do PEDT foram sistematizados e analisados em termos quantitativo e qualitativo. Esses procedimentos foram realizados de modo quase simultâneo, uma vez que o primeiro plano de análise quantitativa indicava a necessidade de um tratamento qualitativo das respostas fornecidas pelos docentes. Isso permitiu refazer e refinar o plano de sistematização das informações para a análise estatística, de modo que a exposição que segue integra esses dois tipos de análise ${ }^{10}$.

\section{Os docentes e sua relação com o trabalho, a universidade e o espaço privado}

Entre os docentes participantes da amostra, 94,8\% trabalham em regime de dedicação exclusiva e têm, em média, 14,6 anos de atividade na universidade - tempo suficiente para se qualificar e acumular experiência tanto na docência como na pesquisa. Esse tempo varia de menos de 3 anos a 34,7 anos, como mostra o Quadro 1.

Quadro 1: Docente e tempo de trabalho

\begin{tabular}{|l|l|l|}
\hline Tempo de trabalho & Freq. & $\%$ \\
\hline Até 3 anos e 11 meses de trabalho & 18 & 18,8 \\
\hline De 4 anos a 9 anos e 11 meses de trabalho & 17 & 17,7 \\
\hline De 10 anos a 14 anos e 11 meses de trabalho & 18 & 18,8 \\
\hline De 15 anos a 19 anos e 11 meses de trabalho & 15 & 15,6 \\
\hline De 20 anos a 24 anos e 11 meses de trabalho & 7 & 7,3 \\
\hline 25 anos ou mais anos de trabalho & 21 & 21,9 \\
\hline Total & 96 & 100,0 \\
\hline
\end{tabular}

Fonte: Elaborada pela autora.

Por um lado, o Quadro 1 informa que, nos últimos anos, tem havido uma renovação do quadro docente da Ufes, pois 18,8\% dos participantes da pesquisa tinham menos de 4 anos de atividade na universidade, quando participaram da pesquisa. Por outro, indica também que $63,6 \%$ dos participantes - percentual correspondente aos professores que têm entre 10 e mais

8 A versão on-line foi programada pelo engenheiro de computação Gustavo Becacici.

9 A pesquisa foi aprovada pelo Comitê de Ética em Pesquisa da Ufes. Após a sistematização das informações do PEDT foi realizada uma segunda etapa, que consistiu em entrevistas em profundidade com um grupo de professores selecionados intencionalmente dentre aqueles que responderam às perguntas do protocolo e, além disso, dispuseram-se a ser entrevistados. As informações obtidas nessa segunda etapa não integram este artigo por ainda se encontrarem em fase de análise.

10 A sistematização das informações estatísticas foi realizada pelo cientista social Flavilio Silva Pereira, que utilizou o programa SPSS, versão 11.5 . 
de 25 anos de trabalho nessa universidade - presenciaram o percurso da reestruturação universitária, no que diz respeito às mudanças na carreira docente e ao conjunto de direitos (modificação no tempo necessário à aposentadoria integral, supressão de adicionais por tempo de serviço - a exemplo do quinquênio -, perda de poder aquisitivo de salário etc.), bem como à expansão da estrutura física (construção e reforma de prédios) e acadêmica (criação de novos cursos de graduação e pós-graduação) etc.

No que se refere à carreira docente, apenas $13,5 \%$ dos participantes da amostra são assistentes. Dentre os demais, $58,3 \%$ são adjuntos e $28,1 \%$, associados. A grande maioria $(80,2 \%)$ tem doutorado e os demais são mestres ou especialistas. Embora $82,5 \%$ das mulheres e $78,6 \%$ dos homens sejam doutores - uma ligeira diferença -, os $13,5 \%$ dos participantes com pós-doutorado são majoritariamente homens.

Esse quadro de elevada titulação dos docentes impacta de maneira significativa os programas de pós-graduação. Nesse caso, 66,7\% dos participantes sinalizaram atuar em pelo menos um programa, em geral na condição de professor permanente. Mantêm-se somente na graduação 33,3\%, estando aí não apenas mestres e especialistas, mas também doutores. Alguns desses últimos apresentam como justificativa para não participar de programas de pósgraduação a elevada exigência de produtividade que esse vínculo implica.

Entre os respondentes, 85,4\% afirmam ter orientandos em cursos de graduação e/ou pós-graduação e 39,6\% supervisionam estagiários. O número de orientandos por professor varia muito, o que vai de 1 a 20 estudantes por docente. Entretanto, chama a atenção o registro de que $41,8 \%$ dos 55 docentes que declaram orientar em cursos de pós-graduação têm entre 4 e 10 orientandos sob sua responsabilidade. O Quadro 2 apresenta a distribuição de alunos de pósgraduação por docente.

\section{Quadro 2: Relação professor/orientando em programas de pós-graduação}

\begin{tabular}{|l|l|l|}
\hline Número de alunos & Freq. & $\%$ \\
\hline 1 Aluno & 9 & 16,4 \\
\hline 2 alunos & 14 & 25,5 \\
\hline 3 alunos & 5 & 9,1 \\
\hline Entre 4 e 5 alunos & 16 & 29,1 \\
\hline Entre 6 a 10 alunos & 7 & 12,7 \\
\hline Entre 11 e 20 alunos & 3 & 5,5 \\
\hline NS/NR & 1 & 1,8 \\
\hline Total & 55 & 100,0 \\
\hline
\end{tabular}

Fonte: Elaborada pela autora.

O número de orientandos por professor costuma ser maior quando os docentes atuam, ao mesmo tempo, em nível de mestrado e doutorado. Em sua maioria, esses docentes também orientam ou supervisionam estudantes de cursos de graduação. O Quadro 3 mostra somente a relação professor/orientando em programas de graduação. Nele é possível observar que um número significativo de docentes tem entre 4 e 20 orientandos. 
Quadro 3: Relação professor/orientando em programas de graduação

\begin{tabular}{|l|l|l|}
\hline Número de alunos & Freq. & $\%$ \\
\hline 1 aluno & 9 & 12,2 \\
\hline 2 alunos & 18 & 24,3 \\
\hline 3 alunos & 10 & 13,5 \\
\hline Entre 4 e 5 alunos & 20 & 27,0 \\
\hline Entre 6 a 10 alunos & 14 & 18,9 \\
\hline Entre 11 e 20 alunos & 2 & 2,7 \\
\hline NS/NR & 1 & 1,4 \\
\hline Total & 74 & 100,0 \\
\hline
\end{tabular}

Fonte: Elaborada pela autora.

Cabe lembrar que essas informações referem-se ao período em que o protocolo foi respondido e que essa realidade sofreu modificações, ao menos em alguns departamentos, por terem realizado novos concursos para professores efetivos ao longo do ano de 2010.

Às vezes, a maior quantidade de orientandos é compensada com alguma redução da carga horária em sala de aula, muito embora docentes vinculados a programas de pósgraduação assumam entre 8 e 12 horas de disciplinas por semestre, independentemente do número de seus orientandos (na graduação e na pós-graduação), de manter produção científica regular na forma de publicação e de estar coordenando pesquisa cadastrada na Pró-Reitoria de Pesquisa e Pós-Graduação da Ufes.

Além das atividades referidas acima, há aquelas que o docente não se obriga sequer a contabilizar. Aqui há o tempo consumido em: elaboração de relatórios de produtividade a pedido de alguma instância da universidade; demandas acadêmicas ou administrativas de atualização de currículo acadêmico ou de informações acerca de sua formação ou qualificação (geralmente, solicitadas mais de uma vez ao ano); leitura e resposta de e-mails de trabalho. Vale a pena registrar que 57,3\% emitem pareceres - com vistas à avaliação de artigos para periódicos científicos ou de projetos para instituições de fomento à pesquisa - e $50 \%$ informam que gastam entre 1 e mais de 2 horas diárias com e-mails relacionados ao seu trabalho.

Algumas anotações de trechos redigidos pelos próprios docentes, quando abordam aquilo que não gostam ou consideram mais problemático em seu trabalho ou na universidade, podem dar a dimensão do que foi exposto anteriormente (Quadro 4) ${ }^{11}$.

Quadro 4: Aspectos considerados problemáticos pelos docentes em seu trabalho ou na universidade

\begin{tabular}{l}
\hline Burocratização, relações ainda patrimonialistas e clientelistas [...], dificuldade no processo de comunicação. \\
\hline $\begin{array}{l}\text { Excesso de burocracia para resolver determinados assuntos, como reformas e/ou pequenos reparos na estrutura } \\
\text { dos prédios. }\end{array}$ \\
\hline $\begin{array}{l}\text { Acúmulo de atividades, considerando os vários relatórios, que poderiam se unificar para o acompanhamento de } \\
\text { um trabalho docente, e excessivas reuniões e comissões. }\end{array}$ \\
\hline [...] entraves burocráticos que consomem energia e atrapalham as relações entre colegas e entre os demais pares. \\
\hline Instituição engessada.
\end{tabular}

Fonte: Elaborada pela autora.

11 Cabe informar que os trechos apresentados nos quadros referem-se apenas às anotações feitas pelos docentes no protocolo de pesquisa disponibilizado de forma impressa e pela internet. Não contemplam, portanto, informações das entrevistas realizadas. 
Importante ressaltar que, nas declarações dos professores, uma parte importante de suas atividades é percebida como desnecessária, um entrave para a produção acadêmica e, por essa razão, surge como desgastante. Assim, a intensificação do trabalho docente se dá, também, pelo acúmulo de tarefas inócuas, que podem ser qualificadas como "perda de tempo" ou mesmo "tempo morto" em termos produtivos.

O conjunto de atividades descrito há pouco ocupa toda a jornada de trabalho dos docentes e, muitas vezes, faz com que eles ultrapassem o tempo regimental de 40 horas semanais. Um computador conectado à internet e um telefone são suficientes para que mantenham seu elo com a instituição, onde quer que estejam. É essa característica do trabalho que permite que $77,1 \%$ dos participantes da pesquisa trabalhem parte significativa da jornada em suas próprias residências - um percentual que se eleva quando se trata das mulheres. Em média, os professores trabalham 18,6 horas semanais em casa, mas há os que afirmam trabalhar mais de 30 horas no espaço doméstico. Isso significa trabalho noturno, mesmo que não haja aulas a ministrar - o que é declarado por $79,2 \%$ dos participantes - e trabalho em finais de semana e em feriados, informado por $81,3 \%$.

Em tais casos, quase a metade dos docentes afirma que isso ocorre porque precisam concluir tarefas pendentes devido à sobrecarga de trabalho durante a semana. Alguns comentários apontam os motivos mais significativos para que estendam a jornada de trabalho para além do período regulamentar (Quadro 5).

Quadro 5: Motivos apresentados por docentes para trabalhar à noite e/ou em finais de semana

\begin{tabular}{|l|}
\hline Porque sempre tem relatórios, projetos, pareceres - que parecem ser “extras” e não são contabilizados na jornada. \\
\hline Por não sobrar tempo durante a semana e/ou para não precisar trabalhar à noite durante a semana. \\
\hline $\begin{array}{l}\text { Dar aula, fazer pesquisa, extensão e ainda assumir cargo administrativo, além de ter que publicar e participar de } \\
\text { bancas, não cabe no tempo. }\end{array}$ \\
\hline O ambiente da universidade não é próprio para trabalhar com concentração; demandas sempre urgentíssimas. \\
\hline Porque são atividades inadiáveis que não cabem no horário normal de trabalho. \\
\hline $\begin{array}{l}\text { Trabalho à noite corrigindo provas, trabalhos, preparando aula. Como exerço cargo administrativo, o tempo que } \\
\text { fico na universidade não dá para fazer algumas atividades de leitura. }\end{array}$ \\
\hline Agilizar trabalhos, corrigir tarefas, elaborar textos, ler e responder e-mails. \\
\hline Para conseguir conciliar atividade de ensino e pesquisa. \\
\hline Carga excessiva de trabalho. \\
\hline Durante a semana, o excesso de aula interrompe o fluxo de ideias e a concentração em leituras densas. \\
\hline Preparar melhor as aulas e escrever artigos. \\
\hline
\end{tabular}

Fonte: Elaborada pela autora.

A literatura que tem discutido o trabalho docente do Ensino Superior constata situação semelhante. Mostra que é comum, diante da intensificação e da sobrecarga de atividades, os professores seguirem trabalhando sem estabelecer limites de horário, o que leva a que essa dinâmica interfira no tempo que deveria ser dedicado às necessidades particulares (Alvarez, 2004; Mancebo \& Lopes, 2004; Lopes, 2006; Bianchetti \& Machado, 2008). Além de as atividades profissionais invadirem o espaço privado, dificultando os limites entre tempo de trabalho e de não trabalho, isso significa que o consumo de recursos necessários a tais atividades fica por conta do próprio professor: custos decorrentes do uso de telefone, celular, computador particular, consumo de energia elétrica etc. Um custo que, obviamente, acaba absorvido em seu orçamento doméstico e desonera a instituição. Os docentes que optam por 
concentrar toda a jornada na universidade estão presentes principalmente nas áreas tecnológicas e de exatas. Mesmo assim, muitos admitem trabalhar em finais de semana e feriados.

O fato de fazer de suas residências uma espécie de extensão da universidade não é percebido como problemático. Ao contrário, isso faz com que expressões como "flexibilidade" e "autonomia" na organização do próprio tempo sejam frequentes no discurso dos docentes, quando solicitados a caracterizarem os aspectos de que mais gostam ou que consideram mais positivos no trabalho propriamente dito ou na universidade.

Muito embora, os professores, em sua maioria, afirmem sentir-se estimulados ou até realizados profissionalmente por causa do contato com os estudantes, da oportunidade de estar em salas de aula, da importante contribuição à sociedade ao formar novos profissionais, é na pesquisa que eles se espelham quando se trata do sentimento de reconhecimento dentro da própria universidade e fora dela.

Entre os participantes, 69,8\% informam ter pesquisa cadastrada em andamento e alguns afirmam trabalhar em até quatro pesquisas simultaneamente. Isso é mais do que os que assinalam exercer alguma função administrativa $(60,4 \%)$ - o que vai desde direção de centro, passando por chefia de departamento e coordenação de curso, até representação em conselhos deliberativos ou participação em comissões internas. Mais importante ainda, isso ultrapassa o dobro dos que declaram coordenar projetos de extensão (30,2\%). Em vários casos, o docente ocupa alguma função administrativa ao mesmo tempo em que coordena projetos de pesquisa e de extensão. Isso é frequente em cursos vinculados a áreas que envolvem aspectos mais diretamente voltados para questões de ordem social, a exemplo dos cursos de Serviço Social, Enfermagem e Medicina.

Em grande medida, a participação em várias pesquisas se dá a partir de parcerias que otimizam a produção de seus integrantes, uma vez que as publicações são assinadas por todos os envolvidos. Entre os docentes, $77,1 \%$ informaram publicar seus trabalhos. O número de publicações varia de 1 a 4 ao ano, considerando a média de um triênio. Em que pese o expressivo número de docentes com pesquisas e publicações, apenas 6,3\% dos participantes têm bolsa produtividade do Conselho Nacional de Desenvolvimento Científico e Tecnológico (CNPq). O maior número de publicações fica por conta dos docentes do Centro Tecnológico. Determinadas características dessa área de conhecimento parecem ser responsáveis por tal desempenho. Trata-se de um campo científico que se fundamenta em resultados de observação e experimentos relativamente controlados, o que marca de forma acentuada a objetividade da exposição de seus estudos, e quase sempre está voltado à produção de tecnologias diretamente aplicáveis.

No que diz respeito à produção acadêmica, os docentes tendem a considerar que há uma "exigência desmedida de produtividade" - leia-se, publicações -, sem que, no entanto, tenham condições objetivas para tal. Alguns comentários podem dar a dimensão dessa consideração. Eles, geralmente, seguem a mesma direção quando se trata de críticas a esse tipo de exigência (Quadro 6). 


\section{Quadro 6: Comentários acerca de exigências de metas de produtividade}

\begin{tabular}{|l|}
\hline $\begin{array}{l}\text { A pressão, cada vez maior, por produtividade, sem a devida melhoria das condições básicas de trabalho, } \\
\text { principalmente infraestrutura - equipamentos em boas condições e suporte administrativo, funcionários em } \\
\text { número suficiente e bem preparados. }\end{array}$ \\
\hline Ser obrigado a publicar sob pressão, não ter tempo para estudar com prazer e calma. \\
\hline $\begin{array}{l}\text { Metas impossíveis de cumprir, ou somente cumpríveis se não trabalhasse adequadamente. Ex.: para publicar } \\
\text { como quer a Capes (ou dizem que ela quer) teria que negligenciar a graduação. }\end{array}$ \\
\hline$[\ldots .$.$] uma cobrança de produção em nível de Primeiro Mundo com condições de Terceiro Mundo.$ \\
\hline$[\ldots .$.$] produtivismo, exigência de publicação a qualquer preço, quantidade e não qualidade.$ \\
\hline $\begin{array}{l}\text { A universidade não valoriza mais o conhecimento ou a leitura e, sim, a produção. Sinto que muito que se } \\
\text { escreve ninguém lê. Sinto que tenho que participar de um mercado acadêmico como qualquer outro mercado. }\end{array}$ \\
\hline O atendimento às normas da Capes, numa produtividade que exclui mais que beneficia instituições como a Ufes. \\
\hline A valorização excessiva do fragmentário, do produtivismo quantitativo em prejuízo da qualidade. \\
\hline
\end{tabular}

Fonte: Elaborada pela autora.

De acordo com os docentes, as principais responsáveis por essa busca de produtividade são as políticas de metas criadas pelas próprias instituições financiadoras e/ou reguladoras de parte do trabalho acadêmico. As instâncias acadêmicas e administrativas da universidade adotam os critérios estabelecidos por tais instituições. Com isso, os docentes veem-se forçados a segui-los, para ser considerados produtivos e para que os programas de pós-graduação aos quais estão vinculados obtenham conceitos suficientemente elevados para possibilitar a aquisição de bolsas e verbas de manutenção ou, simplesmente, para continuar existindo.

Alguns dos participantes defendem a necessidade de critérios de avaliação da produção e do desempenho docente. O que os trechos expostos no Quadro 6 evidenciam é, então, o descontentamento com o grau e o modo de exigência de produtividade, bem como a inexistência de condições compatíveis com tal grau de exigência.

De certo modo, há a preocupação com o risco de se perder de vista o caráter acadêmico e social da produção científica, porque a relevância não está mais focada no resultado ou na contribuição real da pesquisa realizada - quer para a sociedade, quer para o mundo acadêmico -, mas em seu impacto quantitativo no currículo do professor e no programa de pós-graduação no qual atua.

Ao final, como atesta Alvarez (2004), não se trata de buscar produções de qualidade. Ao contrário, tem sido perceptível a acentuada queda de qualidade do conteúdo das dissertações e das teses defendidas por alunos de pós-graduação, dos relatórios de pesquisa que, não raramente, apresentam resultados pobres e de pouca consistência empírica e/ou teórica - e dos artigos, dentre os quais muitos carecem de originalidade e novidade. Defende a autora: "O frenesi de publicar constituiria um tipo de compulsão coletiva trabalhando conjuntamente com um empobrecimento do discurso científico e uma baixa de criatividade" (Alvarez, 2004, p. 229).

A corrida para a manutenção de bolsas de estudo ou para a obtenção de verbas com vistas a equipar laboratórios e salas de estudos, custear viagens a congressos etc. instaura uma verdadeira competição entre os docentes de um mesmo departamento ou programa de pósgraduação. Isso integra os comentários de parte significativa dos participantes da pesquisa (Quadro 7). 
Quadro 7: Comentários sobre competição e rivalidade entre pares e na universidade

\begin{tabular}{|l|}
\hline Rivalidade, competição, falta de companheirismo. \\
\hline Arrogância de alguns que acham que são mais que outros. \\
\hline Relações de poder e dominação de grupos [dentro o próprio departamento]. \\
\hline Vaidade excessiva que há no meio acadêmico. \\
\hline $\begin{array}{l}\text { Em nome de uma autonomia, muitos professores trabalham isoladamente e não se envolvem com a instituição. É } \\
\text { desestimulante também ter que conviver com uma gestão centralizadora, desarticulada e desarticuladora, que } \\
\text { torna o cotidiano quase insuportável. }\end{array}$ \\
\hline
\end{tabular}

Fonte: Elaborada pela autora.

As perspectivas produtivista e competitiva, próprias do mundo globalizado do trabalho, invadiram o mundo acadêmico. As regras estão cada vez mais homogeneizadas e naturalizadas, a ponto de os docentes, em sua maioria, já não perceberem que há certa dose de coação nas políticas acadêmicas que regem, principalmente, os programas de pós-graduação. Consideram que estão numa espécie de caminho sem volta, uma vez que as normas são estabelecidas em instâncias sobre as quais eles não sentem que podem ter algum controle.

O que parece ocorrer aqui, todavia, é o entrelaçamento entre coerção e convencimento. Para Gramsci (1978), as ações coercitivas só têm efeito real na vida dos indivíduos se eles as tornarem válidas pelo consenso, se as dotarem de sentido que julguem próprio, quando se convencem e justificam os atos e pensamentos a partir de si mesmos, e não a partir do que lhes é externo - enfim, quando a ideologia ganha validade psicológica.

Os docentes já internalizaram as regras externas de produtividade, a ponto de buscar produção elevada por uma necessidade que sentem como própria, seja para honrar seus compromissos (reais ou imaginários) com a universidade, seja para se manter competitivos diante de seus pares. Embora ainda se sintam pressionados a produzir, agem como se essa forma de coerção fizesse parte da natureza de seu trabalho e da expectativa normativa da instituição universitária, não se tratando, assim, de determinado momento histórico do mundo acadêmico.

\section{O docente e a precariedade das condições de trabalho}

Dentre os aspectos que os professores identificam como mais críticos em seu trabalho estão, principalmente, a sobrecarga de atividades e a competição, que, muitas vezes, é geradora de tensões entre colegas - temas abordados anteriormente - , bem como a precariedade das condições laborais.

Pouco mais de $2 / 3$ dos docentes qualificam tais condições como "precárias" - adjetivo que corresponde a 22,9\% das expressões registradas nesse item específico -, "péssimas", "insatisfatórias", "ruins" etc., totalizando, assim, 97 adjetivações negativas. Para muitos, trata-se de uma situação geradora de "desestímulo", "insatisfação", "desânimo", "frustração". Em contraste, $40,6 \%$ dos docentes adotam adjetivos mais ou menos positivos, ou mesmo neutros, tais como "boas", "satisfatórias", "razoáveis", "adequadas", "modestas" etc. São, ao todo, 40 expressões com esse conteúdo.

Aqui as noções de precário e precariedade associadas ao trabalho dizem respeito à inadequação das condições objetivas em que as atividades docentes são realizadas. Nesse caso, trata-se de um quadro de longa data que tem caracterizado a universidade, e que revela, muitas vezes, o descaso político, de um lado, e administrativo, de outro, por parte das instâncias superiores da instituição. 
Algumas anotações elaboradas livremente pelos próprios docentes são um indicativo relevante de como percebem e avaliam esse aspecto do trabalho. No caso em questão, julgo importante identificar, ao menos, o centro ao qual o departamento do docente está vinculado. Com isso, podemos notar que se trata de uma percepção relativamente homogênea entre as diversas áreas de conhecimento da universidade, o mesmo verificando-se no que tange aos aspectos relativos à sobrecarga de trabalho, à produtividade e ao clima competitivo. Os comentários pertinentes foram organizados em dois quadros (8 e 9) para melhor visualização de seu conteúdo.

\section{Quadro 8: Comentários sobre a precariedade das condições de trabalho na universidade}

Centro de Ciências Humanas e Naturais (CCHN)

Desgastantes, aulas boas em decorrência da experiência; equipamentos bons [computadores, datashow etc.], salas pequenas [tendo entre 4 e 5 metros quadrados, ocupadas por 2 ou 3 professores], sujas, desconfortáveis, divididas com mais 3 professores e dezenas de alunos em fluxo variável, com todo mundo utilizando 3 computadores.

Condição deplorável; péssimo acesso a recursos didáticos - nem temos alguém para carregar e montar o equipamento em sala de aula. Não há recursos (computadores, softwares, possibilidade de tirar cópias de questionários ou ter acesso a programas de pesquisa on-line) fornecidos pela universidade. Todos os recursos vêm de fontes externas, quando conseguimos acesso a elas.

Condição predial deficitária, oferecendo riscos à segurança e à vida. O prédio precisa de reformas e, há mais de 10 anos, nem pintura tem sido feita. O aspecto do local de trabalho é desagradável e desconfortável para quem traz pesquisadores de outras instituições.

Vão de péssimo - quando se trata de serviços prestados pela universidade (como telefone, luz, água, arcondicionado, computadores, internet etc.) - ao excelente, quando se trata dos equipamentos para pesquisa, graças ao enorme esforço individual e coletivo para obtenção de recursos externos.

São boas, mas poderiam ser melhores.

Condições de trabalho limitadíssimas, beirando, em muitos casos, o improviso.

Centro de Educação (CE)

Considero que as condições de trabalho oferecidas não são boas. O que tem possibilitado melhorá-las são os projetos financiados pelo CNPq, Capes, Fundação de Amparo à Pesquisa do Espírito Santo (Fapes), entre outros.

Regular para ruim.

As condições são ótimas; o tempo é que tem sido muito curto.

Inadequadas, insalubres.

Centro de Ciências Jurídicas e Econômicas (CCJE)

Um lixo. Não se dispõe nem de retroprojetor, uma tecnologia rígida e ultrapassada. Datashow, nem pensar! Seria maravilhoso! A refrigeração das salas de aula é péssima. Ventiladores de teto e com barulho...

Muito precárias, equipamentos sempre com problemas, problemas na rede da Ufes. Nas salas de aula temos problemas com funcionamento de retroprojetores. Em tempos de verão é muito incômodo, pois o calor e a claridade nas salas de aula trazem prejuízos para a atividade de ensino-aprendizagem.

As condições são satisfatórias, no mínimo. Especialmente as salas de aula são muito precárias, comprometendo as aulas.

Considero que a situação é boa, podendo ser melhorada em vários aspectos, mas não impeditivas de trabalho sério.

Fonte: Elaborada pela autora. 
Quadro 9: Comentários sobre a precariedade das condições de trabalho na universidade

\begin{tabular}{|l|}
\hline Centro de Ciências da Saúde (CCS) \\
\hline $\begin{array}{l}\text { Nesse momento, temos tido dificuldades com as salas de aula no sentido de o número delas ser insuficiente para } \\
\text { atender a demanda do departamento. As salas improvisadas têm cheiro de tinta muito forte, o que prejudica a } \\
\text { saúde de professores e alunos. Os recursos didáticos são melhores, minha sala é razoável, faltam armários. }\end{array}$ \\
\hline Adequadas, considerando a situação anterior, em que [as condições] eram piores. \\
\hline Inadequadas, insuficientes - desestimuladoras. \\
\hline $\begin{array}{l}\text { Salas de aula com instalações físicas extremamente precárias, ambulatórios médicos em péssimas condições, } \\
\text { precariedade de material assistencial, equipamentos didáticos obsoletos e precários, falta de acesso a recursos } \\
\text { didáticos. }\end{array}$ \\
\hline Centros Tecnológico (CCT) e de Ciências Exatas (CCE) \\
\hline $\begin{array}{l}\text { Salas de aula sofríveis, longe do século XXI. Recursos didáticos escassos. Minha qualidade de vida na } \\
\text { organização: sinto-me sem reconhecimento e, às vezes, um lixo perante a administração da universidade. }\end{array}$ \\
\hline De deficitária a, no máximo, razoável. \\
\hline Escasso quanto ao acesso a recursos; deplorável para minha sala, que é provisória desde sempre. \\
\hline $\begin{array}{l}\text { As condições são ruins e desrespeitosas com o profissional (professor) que atua com tanta seriedade. Os alunos } \\
\text { também sofrem devido a isso, com salas quentes, sem local adequado para estudo devido à falta de espaço etc. }\end{array}$ \\
\hline Boas, mas com necessidade de melhorias. \\
\hline $\begin{array}{l}\text { No geral, as condições são boas. Mais especificamente, veja discriminação abaixo: salas de aula - fraco; acesso a } \\
\text { recursos didáticos - regular; acesso a recursos de pesquisa - bom; salas de atendimento - excelente (tenho uma } \\
\text { sala individual muito boa). }\end{array}$ \\
\hline $\begin{array}{l}\text { Precárias; salas de aula ruins; falta de quadros brancos; sem ar-condicionado; turmas cheias; sem condições } \\
\text { mínimas de organização em colegiados. }\end{array}$ \\
\hline Fonte: Elaborada pela autora. \\
\hline
\end{tabular}

A descrição das condições de trabalho feita pelos docentes mostra que, em se tratando de recursos tecnológicos, o quadro pode ser considerado entre razoável e bom, pelo menos em alguns departamentos. Entretanto, sabemos que esse tipo de suprimento se deve ao empenho dos próprios professores, que buscam financiamentos para desenvolver suas pesquisas. Assim, os centros que aglutinam cursos voltados para áreas do chamado conhecimento hard acabam tendo mais recursos dessa ordem.

Quando se trata das condições de infraestrutura predial e de equipamentos não tecnológicos - responsabilidade exclusiva da administração superior da universidade -, a situação se modifica. Aqui o contraste é brutal: salas e laboratórios com computadores de última geração convivendo com mesas, armários e aparelhos de ar-condicionado antigos e em más condições de conservação; salas de aula de alguns departamentos equipadas com datashow, computador, TV e DVD e, ao mesmo tempo, com ventiladores ruidosos, lâmpadas queimadas, janelas e portas que não se fecham adequadamente. São as características problemáticas das condições de trabalho que mais chamam a atenção dos docentes e que, em parte, tornam seu trabalho motivo de descontentamento, desânimo, cansaço e, até, de sofrimento.

Um aspecto importante que reforça a percepção que os docentes têm desse nível de precariedade do trabalho está no fato de que mais de $2 / 3$ deles assinalam ministrar aulas em volume de voz elevado. Muitos afirmam já sentir prejuízo no desempenho vocal, como veremos adiante.

As condições de trabalho, somadas à sobrecarga laboral, às exigências de produtividade e ao clima de competição, fazem com que os professores tendam a expressar mais sentimentos negativos do que positivos em relação à atividade docente e à própria universidade. 


\section{Sentimentos em relação ao trabalho: entre o produto invisível e a produtividade palpável}

O instrumento adotado na pesquisa apresentava um quadro de proposições indicativas de possíveis sentimentos em relação ao trabalho. Elas foram elaboradas, em parte, tomando por base itens da escala Maslach para estudo de burnout ${ }^{12}$, sem que, no entanto, tivessem o propósito de analisar essa síndrome. Assim, a análise das informações obtidas levou em conta apenas se tais sentimentos poderiam ser qualificados como positivos ou negativos e a que se referiam. Cabe sublinhar que os docentes podiam assinalar os enunciados que mais se aproximassem de sua própria realidade.

Dentre os participantes da pesquisa, $71,9 \%$ assinalaram estar influenciando positivamente a vida de outras pessoas, $42,7 \%$ expressam que se sentem estimulados ao trabalhar com alunos ou que criam ambiente tranquilo em sua relação com eles - o que não se verifica em percentual similar quando se trata da relação com colegas -, 54,2\% consideram que têm realizado coisas importantes em seu ofício e, por fim, 39,6\% informam sentir-se produtivos (Quadro 10).

\section{Quadro 10: Sentimentos positivos em relação ao trabalho}

\begin{tabular}{|l|l|l|}
\hline Sentimentos em relação ao trabalho & Freq. & $\%$ \\
\hline Sente que está influenciando positivamente a vida de outras pessoas. & 69 & 71,9 \\
\hline Sente-se estimulado(a) depois de trabalhar com seus alunos. & 41 & 42,7 \\
\hline Sente que pode criar facilmente um ambiente tranquilo com seus alunos. & 41 & 42,7 \\
\hline Considera que tem realizado muitas coisas importantes como docente. & 52 & 54,2 \\
\hline Tem-se sentido produtivo(a) nos últimos dois anos. & 38 & 39,6 \\
\hline Total & 96 & 100,0 \\
\hline
\end{tabular}

Fonte: Elaborada pela autora.

Como podemos notar, os sentimentos caracterizados como positivos estão relacionados, fundamentalmente, ao sentido mais intrínseco e subjetivo do trabalho docente. Nesse caso, são aspectos sobre os quais os professores podem deter importante grau de controle, tendo em vista que dizem respeito ao principal objetivo da docência e ao modo como se veem como profissionais.

Assim, são frequentes comentários acerca da relação com os estudantes como um aspecto do trabalho que traz gratificação e prazer - pois se trata de uma convivência com "jovens que buscam conhecimento" -, ou, então, sobre a natureza do próprio trabalho, que permite dar vazão à criatividade e ao exercício da autonomia. $\mathrm{O}$ contato com os alunos e a oportunidade de acompanhá-los em seu amadurecimento intelectual são, para muitos docentes, os maiores trunfos da carreira de um professor. Aqui não há pressão por produtividade, mas certo deleite e determinada compensação, uma vez que percebem sua importância na vida de pessoas que estão se preparando para o mundo do trabalho.

12 O burnout é também chamado de "síndrome da desistência", ou, ainda, "neurose de excelência", e refere-se a um problema que tem acometido trabalhadores cujas atividades envolvem, fundamentalmente, o cuidado ou o contato direto e excessivo com pessoas (Benevides-Pereira, 2002). Caracteriza-se por sua "evolução lenta, com piora progressiva e severa" (Lacaz, 2010, p. 56). A avaliação do burnout é feita através de um instrumento de autoinforme denominado Maslach Burnout Inventory (MBI), constituído por 22 itens que consideram as 3 dimensões que compõem a síndrome: exaustão emocional, despersonalização e baixa realização profissional (Benevides-Pereira, 2002; Lacaz, 2010). 
Elementos como esses estão presentes em estudos que discutem trabalho, sofrimento e prazer no universo docente (Mancebo \& Lopes, 2004; Mancebo, 2007). No entanto, a presença de aspectos considerados gratificantes e prazerosos não levam os professores, em sua grande maioria, a se sentir produtivos. Os que responderam que se sentiam produtivos estavam, majoritariamente ( $81,6 \%$ dos 38 participantes), atuando em pós-graduação - portanto, diante da obrigatoriedade de ter pesquisa em andamento e, sobretudo, de publicar trabalhos científicos.

Isso demonstra que o sentimento de ser produtivo praticamente se reduz às atividades cujos produtos possam ser quantificáveis, por ser palpáveis: o trabalho intelectual precisa se materializar em um objeto, uma coisa, algo que possa ser visto, tocado, sentido. Um texto escrito pode ser impresso, lido, debatido, ou apenas tornar-se descartável, como qualquer objeto que não tem mais serventia. Assim, a chamada produção científica, materializada em artigos, capítulos ou livros, parece tornar-se equivalente a qualquer bem material, cuja produção segue metas quantitativas que precisam ser cumpridas.

Do que se pode notar, no meio acadêmico, passou-se a adotar sistemas de metas similares aos dos setores de produção de bens materiais, para atender à demanda de determinados "clientes", que, nesse caso, são as instituições que financiam, regulam, avaliam e controlam as atividades de pesquisa e pós-graduação nas universidades - mais especificamente, instâncias como o CNPq e a Capes.

Diante do exposto, é possível afirmar que os docentes estão começando a negar o caráter imaterial do trabalho e, ao mesmo tempo, se agarrando ao que, aparentemente, tem alguma materialidade. O ensino, a formação de profissionais para o mundo do trabalho, seja ele acadêmico ou não, parece estar perdendo espaço para a pesquisa e a publicação, não importando quão relevantes elas sejam, do ponto de vista científico ou social.

Não se trata, necessariamente, de uma atitude consciente ou proposital, mas o recado implícito pode ser: os estudantes passam pela universidade e, ao sair dela, não há qualquer controle sobre o que vão fazer com o que aprenderam (ou deixaram de aprender) na vida acadêmica; assumir a chefia de um departamento ou a coordenação de um curso é, no fundamental, assumir uma carga de trabalho burocrático e uma grande oportunidade de se tornar alvo de críticas dos pares e de tensões com os colegas; participar de comissões ou representações é assumir uma tarefa cujo resultado é invisível aos olhos de todos.

Ao final, o que sentem, de fato, é a sobrecarga de trabalho, além das condições inadequadas de trabalho, da jornada sem delimitação clara de tempo e - para muitos - da pressão pelo cumprimento de metas de produtividade. Esse conjunto de elementos está na base de uma percepção mais negativa do que positiva do trabalho.

Dentre os participantes, 43,8\% assinalaram que estão trabalhando demais, enquanto apenas 18,8\% expressam trabalhar de modo regular, sem exagero, produzindo o necessário durante a jornada; $34,4 \%$ informam que não se sentem produtivos, apesar de trabalhar muito; $28,1 \%$ indicam que se sentem esgotados ao final do dia ou cansados ao se levantar pela manhã; $71,9 \%$ sentem-se desestimulados ao trabalhar com colegas; $67,7 \%$ referem insatisfação salarial; e 55,2\% avaliam que o trabalho docente não é socialmente valorizado. $O$ Quadro 11 sintetiza tais sentimentos. Nele, nem todos os enunciados estão exatamente de acordo com os do instrumento adotado. Alguns foram categorizados de modo a dar maior visibilidade aos resultados encontrados. 
Quadro 11: Sentimentos negativos em relação ao trabalho

\begin{tabular}{|l|l|l|}
\hline Sentimentos em relação ao trabalho & Freq. & $\%$ \\
\hline Avalia que está trabalhando demais na universidade. & 42 & 43,8 \\
\hline $\begin{array}{l}\text { Considera que, mesmo produzindo muito, não tem tido o devido reconhecimento por seu } \\
\text { esforço. }\end{array}$ & 32 & 33,3 \\
\hline Sente que não tem sido produtivo(a), apesar de trabalhar muito. & 33 & 34,4 \\
\hline Sente-se esgotado(a) ao final de um dia de trabalho. & 27 & 28,1 \\
\hline Sente-se cansado(a) ao se levantar de manhã para encarar outro dia de trabalho. & 27 & 28,1 \\
\hline Sente-se desestimulado(a) ao trabalhar com colegas. & 69 & 71,9 \\
\hline Sente-se insatisfeito com o salário. & 65 & 67,7 \\
\hline Sente que o trabalho docente não é socialmente valorizado. & 53 & 55,2 \\
\hline Total & 96 & 100,0 \\
\hline
\end{tabular}

Fonte: Elaborada pela autora.

O conteúdo das proposições que mais se destacam está relacionado, em especial, a aspectos que dizem respeito à carga de trabalho e às consequências ou desdobramentos de seu excesso (cansaço, esgotamento), ou, então, a aspectos sobre os quais os docentes têm pouco ou nenhum controle, a exemplo da situação salarial. Não há referência negativa diretamente associada à natureza do próprio trabalho, como ensinar, pesquisar, escrever. As tensões nas relações interpessoais envolvem os colegas, mas não os estudantes. Nesse caso, é possível indicar a dinâmica competitiva entre os pares como sendo um dos pontos geradores de desconforto. $\mathrm{O}$ sentimento de trabalhar em excesso, mas não se sentir produtivo, pode estar relacionado à obrigatoriedade de realizar tarefas inócuas - ou, de fato, não produtivas -, bem como à percepção de que a produção acadêmica está centrada na pesquisa e na publicação. Daí, o cansaço e o esgotamento podem ter como base não só o trabalho excessivo, mas o sentimento de insatisfação pessoal com o resultado final de uma jornada de trabalho e a percepção do não reconhecimento social pelo esforço empreendido.

Dentre os que responderam sentir-se esgotados ao final do dia, 63\% estão em programas de pós-graduação, 88,9\% procuraram assistência de algum profissional de saúde e $85,2 \%$ informam que sentem desconforto ou mal-estar físico ou psíquico, sem, no entanto, qualificar esses sinais como importantes para justificar a busca de ajuda profissional. Alguns desses desconfortos são: fadiga, dores no corpo ou nas pernas, estresse etc.

Situação parecida ocorre aos que informaram sentir cansaço ao se levantar, pela manhã, para trabalhar. Nesse caso, 96,3\% procuraram ajuda de profissionais de saúde, $63 \%$ fazem uso de medicação prescrita e 85,2\% referem desconforto ou mal-estar físico e psíquico.

Sendo assim, o que qualifiquei como expressões de sentimentos acerca do trabalho tem forte relação com a saúde ou o sofrimento dos docentes, razão por que julgo importante desdobrar tal problema.

\section{Sofrimento e adoecimento: expressões das mazelas do trabalho docente}

Dentre os participantes, $78(81,3 \%)$ assinalaram ter procurado atendimento médico e/ou psicológico nos últimos dois anos. Desse conjunto, 46,2\% fizeram-no entre 1 e 2 vezes por ano. No mesmo grupo, 36\% - 18 mulheres e 10 homens, totalizando 28 participantes - 
apresentam queixas relacionadas a agravos de ordem psicoemocional (principalmente depressão e ansiedade), 14,1\% referem enxaqueca, cistite e crise gástrica - que também pode ter como desencadeante a dimensão psicoemocional - e 12,8\% informaram ter afecções osteomusculares. Há, ainda, relatos de afecções como hipertensão, diabetes e distúrbios hormonais.

Embora o burnout não seja o foco da discussão desenvolvida neste artigo, é possível apontar que os sinais mais frequentes de sofrimento ou adoecimento entre os docentes são aqueles relacionados a essa síndrome, tal como descreve Lacaz (2010): exaustão mental e emocional, fadiga e depressão. São sintomas que têm em sua base elementos como exigências de produtividade e excelência e, ao mesmo tempo, dificuldades para o cumprimento de tais exigências. Para Aubert (1993, p. 187-88), trata-se de um fenômeno que surge como resultado da "necessidade de trabalhar energicamente, de envidar cada vez mais esforços, de desempenho cada vez melhor e de tender sempre para um maior sucesso". Pelo que foi exposto até aqui, essas são características fundamentais no trabalho docente, na atualidade. Portanto, não causa estranheza que encontremos associações entre determinadas queixas dos professores e a síndrome de burnout.

Os problemas mais frequentes relatados pelos docentes não se restringem a transtornos designados como de ordem psicoafetiva ou aos que possam ter a dimensão psicoemocional como desencadeante principal de alguma afecção de expressão somática. Dos participantes da pesquisa, 64,6\% assinalaram que ministram aula com algum nível de esforço vocal e 28,1\% já sentem desconforto e irritação na região da garganta. Sobre esse assunto, há duas observações dignas de nota. A primeira diz respeito às mulheres, que são as que mais sofrem os prejuízos das condições inadequadas de trabalho. É muito provável que isso se deva ao fato de que elas, comumente, têm voz com menor volume que os homens, o que as obriga ao esforço vocal para serem ouvidas. A segunda observação tem a ver com a relação entre esforço vocal e quantidade de horas-aula semanais. Nesse caso, esse tipo de esforço, com ou sem desconforto e irritação, tende a aparecer mais entre os docentes que ministram nove ou mais horas-aula semanais.

De maneira geral, os motivos apontados pelos próprios docentes são: em primeiro lugar, conversas paralelas entre os alunos e ruídos dos aparelhos de ar-condicionado ou dos ventiladores antigos e sem manutenção; em segundo, acústica deficiente das salas de aula, ruídos provocados por construções e reformas de prédios e limpeza do campus - estas realizadas, com frequência, nos horários reservados às aulas na universidade; em terceiro lugar, excesso de alunos em sala. Essa caracterização das condições em que ministram suas aulas integra os comentários da maioria dos docentes, independentemente de terem assinalado qualquer dificuldade ou prejuízo no uso da voz. Alguns docentes, diante dos problemas que passaram a sentir, tomaram a iniciativa de adquirir, com recursos próprios, microfone e amplificador de voz.

Há, aqui, um elemento que deve ser considerado. É possível argumentar que 9 ou 12 horas de aula durante uma semana não seriam suficientes para comprometer a voz de um professor, mesmo que ele esteja exposto a situações que o obriguem a determinado esforço vocal. Temos, entretanto, que levar em conta, nesse caso, um ponto importante: os docentes procuram organizar de modo racional sua jornada de trabalho, concentrando as atividades de ensino em poucos dias da semana, com a finalidade de dispor de mais tempo para suas pesquisas, encargos administrativos, viagens para participação em bancas ou em congressos, elaboração de trabalhos científicos etc. Assim, assumem ministrar, em condições inadequadas, 4 horas num mesmo turno, ou até 6 horas em dois turnos próximos, tendo curtos intervalos para repouso. Além disso, não raramente, sentem-se diante da necessidade de concluir o conteúdo planejado para aquele dia, como mostra a seguinte afirmação apresentada, por uma professora, no protocolo de pesquisa: 
[o esforço vocal, com irritação na garganta] ocorre porque há muita conversa. Na sala tem 45 alunas, e é tradição do curso dispor as cadeiras coladas uma às outras. Paro muito para chamar a atenção, mas, às vezes, na ansiedade de completar o planejamento do dia, vou "esticando" a voz e postergando a parada disciplinar.

O comprometimento da voz pode ser esperado nos casos em que há concentração de tempo de aula em 1 ou 2 turnos. De acordo como Luchesi, Mourão, Kitamura e Nakamura (2009), a tentativa do docente em modificar sua voz, para alcançar um padrão considerado adequado, leva-o a produzir ajustes musculares inadequados que perduram durante todo o dia de trabalho, o que resulta em fadiga e alteração da qualidade vocal.

Além disso, é comum os docentes serem procurados por alunos, mesmo nos intervalos entre uma aula e outra, de modo que raramente conseguem repousar a voz até o início ou a retomada de uma aula.

As informações acerca da saúde dos docentes, como as aqui discutidas, não se restringem à Ufes. Pesquisa realizada na Universidade Federal Fluminense (UFF), utilizando, em parte, informações da Divisão de Saúde Ocupacional da própria instituição, mostra que, em 2007, 194 docentes procuraram aquele serviço - 124 (63,9\%) mulheres e 70 (36,1\%) homens. Os diagnósticos prevalentes foram os transtornos mentais e comportamentais, envolvendo 20 mulheres e 9 homens, seguidos de doenças do sistema nervoso, que acometeram 17 mulheres e 6 homens (Emiliano, 2008).

Apesar das diferenças quanto às abordagens metodológicas, a pesquisa que acaba de ser citada e a que desenvolvi apontam na mesma direção: a predominância de determinados modos de adoecimento ou de sofrimento, relacionados, em sua maioria, a queixas psicoemocionais, e o segmento feminino revelando-se como mais suscetível a tais problemas do que o segmento masculino ${ }^{13}$.

Não foi possível obter informações acerca dos diagnósticos que embasam os pedidos de licença médica encaminhados por docentes ao Serviço de Perícia Médica da Ufes. Sendo assim, as únicas informações oficiais, dessa universidade, são as do departamento de Recursos Humanos (DRH). Entre 2008 e 2009, houve apenas 140 licenças médicas concedidas a professores. Isso, entretanto, não expressa o quantitativo real de casos de adoecimento na categoria. O DRH não registra os diagnósticos específicos que motivam os afastamentos por doença.

Essa situação indica que o sofrimento e o adoecimento dos professores parecem passar despercebidos na universidade. Uma possível explicação é que a natureza específica do trabalho do docente permite que não se notifiquem os casos efetivos de afastamento por problemas de saúde. Assim, em geral, o adoecimento do professor é experimentado na esfera privada, permanecendo invisível (ou quase) aos olhos dos colegas e, em especial, da instituição. Uma invisibilidade semelhante a determinadas atividades que ele realiza, as quais estão na base da sobrecarga de trabalho - que, por sinal, contribui significativamente para os agravos à saúde. $\mathrm{O}$ adoecimento torna-se conhecido quando o docente se vê obrigado a se afastar de suas atividades didáticas, assegurado por licença médica que fundamente a necessidade de sua substituição em sala de aula.

Não sendo assim, o professor adoece, procura ajuda de profissionais de saúde fora da instituição, afasta-se por períodos relativamente curtos (uma ou mais semanas) por impossibilidade ou incapacidade de ministrar aulas. Todavia, logo que possível, retorna, reorganiza seu programa de aulas e repõe o conteúdo possível ou o que julga necessário. Às vezes, mesmo doente, continua trabalhando em sua residência. $O$ computador, o telefone e a internet permitem que esse elo com seu trabalho e com a própria universidade seja mantido.

13 Sobre o tema "trabalho, saúde e gênero" em relação aos docentes, consultar Borsoi e Pereira (2011). 
No fim, tudo se passa como se nada tivesse acontecido no âmbito da instituição pública universitária.

Independentemente de declarar ou não alguma queixa referente à saúde, parte dos docentes associa diversos prejuízos na vida pessoal ou na saúde, sobretudo, à situação de trabalho. A análise dos resultados indica o fundamento dessa percepção.

A carga de trabalho, tida como excessiva para a maioria dos docentes, a flexibilidade da jornada de trabalho e a constante exigência de produtividade fazem com que, na prática, os docentes encontrem pouco tempo, de fato, liberado do trabalho. De certo modo, tornam-se "reféns da produtividade", como afirmam Bianchetti e Machado (2008). Assim, a vida na esfera do não trabalho acaba sendo comprometida, em grande medida, pela dimensão das atividades docentes.

Se o tempo liberado do trabalho é escasso, o tempo realmente livre o é ainda mais. Essa situação interfere na vivência do lazer e do descanso propriamente ditos que, no caso dos docentes da Ufes, é bastante restrita. Tanto os finais de semana e feriados como as férias costumam ser invadidos, de alguma maneira, por demandas de trabalho. Uma realidade compartilhada por professores de outras universidades, como mostram os estudos já referidos.

Aspectos como esses refletem, de certa forma, a condição precária que caracteriza o trabalho docente na atualidade e fazem com que seja possível compreendermos por que há, entre os docentes, mais referências a descontentamentos, sofrimento e adoecimento do que prazer, saúde e bem-estar.

\section{Considerações finais}

A discussão levada a cabo neste artigo partiu da consideração de que o trabalho docente é imaterial por excelência, e girou em torno da constatação de que, nas universidades públicas federais, ele está sendo executado em condições precárias em termos de infraestrutura material e de apoio administrativo; tem sido caracterizado pela sobrecarga de trabalho e por forte exigência de cumprimento de metas produtivistas; e está reorganizando intensamente o modo de viver dos docentes, dentro e fora do espaço institucional. Isso tem levado a prejuízos importantes para sua saúde. Trata-se de uma constatação que corrobora os resultados de outras pesquisas realizadas acerca do trabalho de professores do Ensino Superior.

Mesmo que as atividades dos docentes impliquem uma intensa exigência cognitiva e eles despendam tempo em jornadas que, muitas vezes, ultrapassam 40 horas semanais, o resultado de seu esforço é, em geral, impalpável. Ministrar aulas, pesquisar, participar de reuniões deliberativas, orientar estudantes - tudo isso faz parte de uma produção quase sempre invisível aos olhos da própria comunidade acadêmica e, em particular, aos daqueles que estão fora dessa coletividade. Muitas de suas tarefas são, de fato, não produtivas e apenas furtam tempo significativo de uma jornada, nada acrescentando ao docente e à instituição. Isso é caracterizado como extremamente oneroso e é percebido como uma demanda que "emperra a produção acadêmica". Mas não apenas isso. Esse "emperrar" a produção acadêmica conduz o docente a se sentir improdutivo, apesar de considerar que trabalha em demasia.

O trabalho produtivo, aos olhos do docente, restringe-se, então, à chamada "produção científica" - no fundamental, publicações e apresentação de trabalhos em eventos científicos. É assim que ele tem o vislumbre da materialidade do que faz, parece encontrar elo com os trabalhadores "típicos" e começa a tomar ciência de que o trabalho docente, mesmo em seu caráter imaterial, é realizado por sujeitos que também são trabalhadores. 
Essa busca de materialidade, visibilidade, concretude, para um trabalho imaterial pode explicar, na dimensão subjetiva, a excessiva preocupação com a quantidade de publicações passível de ser registrada no currículo acadêmico e de ser confirmada nos sites de revistas científicas ou nas prateleiras das livrarias e das bibliotecas. Entretanto, é preciso considerar a dimensão objetiva do problema, que já parece naturalizada entre os docentes: essa produtividade científica segue políticas de metas criadas por instituições que financiam e/ou controlam parte do trabalho acadêmico. Ambas as dimensões se imbricam e parecem confundir os próprios docentes, que já não têm clareza suficiente de por que, de fato, precisam publicar seus trabalhos. É possível deduzir que se trata de um processo no qual a ideologia adquire validade psicológica, para adotar uma perspectiva gramsciana, já apontada em outra passagem deste artigo.

O professor tem a ilusão de que ainda tem todo o controle sobre o trabalho. $\mathrm{Na}$ realidade, o que, quanto e em que ritmo produzir integram, em grande medida, um sistema de controle institucional que o submete, mas que, a ele, parece fazer parte de uma autonomia acadêmica cada vez menos real. Esta, na prática, tem restringido-se a aspectos do trabalho tais como os conteúdos das disciplinas que ministra e a possibilidade de realizar grande parte do trabalho fora do espaço físico da instituição.

Essa dimensão da autonomia, que se caracteriza pela não obrigatoriedade de o professor permanecer na universidade durante toda a jornada, tem implicado, na realidade, a invasão sem limites da esfera privada pela esfera laboral, uma vez que a fronteira entre os tempos do trabalho e do não trabalho deixou de ser claramente reconhecida, tanto no plano cronológico como no subjetivo. Assim sendo, as dimensões pessoal e profissional passam a gravitar quase que de maneira integral em torno do trabalho e de suas mazelas.

Os professores frequentemente questionam a sobrecarga de atividades, o trabalho noturno e nos finais de semana, a falta de tempo livre etc., mas já consideram tudo isso parte dos "ossos do ofício". Aqui, a autonomia acadêmica - conquista de longa data - e a "flexibilidade" laboral - imposição dos novos tempos - parecem tornar-se sinônimos.

Para concluir, cabe ressaltar que não há dúvida de que os docentes de universidades públicas federais gozem o conforto e a segurança da estabilidade no trabalho. Contudo, essa estabilidade está tendo um preço consideravelmente elevado. Todos estão sendo pressionados a se empenhar e a investir em produtividade, principalmente em termos quantitativos - não importa em que condições objetivas essa produção se efetive e qual a qualidade do produto desse trabalho. Estão sendo instigados a adotar comportamentos competitivos entre seus pares, mesmo que isso sacrifique a qualidade da produção acadêmica e possa gerar sofrimento e adoecimento - que ainda passam despercebidos pelos colegas e pela própria administração universitária.

Dessa forma, mesmo que se fale em realização profissional e prazer no trabalho - com certeza, aspectos relevantes que precisam ser discutidos e, sobretudo, conquistados -, não há como negar que sofrimento e adoecimento têm sido os principais motivos para que o trabalho docente passe a integrar o campo de preocupação das associações representativas da categoria e de profissionais de saúde do trabalhador. Não há como negar, ainda, que, tal como se dá com a invisibilidade da maioria das atividades dos docentes e das ausências motivadas por doenças, também tem sido pouco perceptível que muitos docentes, em grande medida, estão pondo o compromisso com seus alunos, seus colegas, sua produção científica - enfim, sua instituição acima de suas necessidades e condições pessoais. 


\section{Referências}

Alvarez, D. (2004). Cimento não é concreto, tamborim não é pandeiro, pensamento não é dinheiro! Para onde vai a produção acadêmica? Rio de Janeiro: Myrrha.

Antunes, R. (2006). O caracol e sua concha: ensaios sobre a nova morfologia do trabalho. São Paulo: Boitempo.

Aubert, N. (1993). A neurose profissional. In J. F. Chanlat (Org.), O indivíduo na organização: dimensões esquecidas (pp. 163-193). São Paulo: Atlas.

Benevides-Pereira, A. M. T. (2002). Burnout: o processo de adoecer pelo trabalho. In A. M. T. Benevides-Pereira (Ed.), Burnout: quando o trabalho ameaça o bem-estar do trabalhador (pp. 21-91). São Paulo: Casa do Psicólogo.

Bianchetti, L. \& Machado, A. M. N. (2008). "Reféns da produtividade": sobre produção de conhecimento, saúde dos pesquisadores e intensificação do trabalho na pós-graduação. GT: Trabalho e Educação, 9. Anped.

Borsoi, I. C. F. (2011, janeiro/abril). Vivendo para trabalhar: do trabalho degradado ao trabalho precarizado. Convergencia: Revista de Ciencias Sociales, 55, 113-133.

Borsoi, I. C. F. \& Pereira, F. S. (2011, janeiro/junho). Mulheres e homens em jornadas sem limites: docência, gênero e sofrimento. Temporalis, 21, 119-145.

Emiliano, N. (2008). Sociabilidades e adoecimento nas universidades: a saúde do trabalhador na Universidade Federal Fluminense. Dissertação de Mestrado, Programa de Estudos Pós-Graduados em Política Social, Universidade Federal Fluminense, Niterói, RJ.

Gramsci, A. (1978). Americanismo e fordismo. In A. Gramsci, Obras escolhidas (pp. 311-339). São Paulo: Martins Fontes.

Lacaz, F. A. C. (2010, janeiro). Capitalismo organizacional e trabalho: a saúde do docente. Universidade e Sociedade, 45, 51-59.

Lopes, M. C. R. (2006). "Universidade produtiva" e trabalho docente flexibilizado. Estudos e Pesquisas em Psicologia, $6(1), 35-48$.

Luchesi, K. F., Mourão, L. F., Kitamura, S., Nakamura, H. Y. (2009, outubro/dezembro). Problemas vocais no trabalho: prevenção na prática docente sob a óptica do professor. Saúde e Sociedade, 18 (4), 673-681.

Mancebo, D. (2007). Trabalho docente: subjetividade, sobreimplicação e prazer. Psicologia: Reflexão e Crítica, 20 (1), $74-80$.

Mancebo, D. \& Lopes, M. C. R. (2004). Trabalho docente: compressão temporal, flexibilidade e prazer? Revista de Educação Pública, 13 (24), 138-152.

Silva Junior, J. R. (2005). Pragmatismo e populismo na educação superior nos governos FHC e Lula. São Paulo: Xamã.

Sguissardi, V. \& Silva Junior, J. R. (2000). Reforma da educação superior no Brasil: renúncia do Estado e privatização do público. Revista Portuguesa de Educação, 13 (2), 81-100.

Sguissardi, V. \& Silva Junior, J. R. (2009). Trabalho intensificado nas federais: pós-graduação e produtivismo acadêmico. São Paulo: Xamã.

\section{Endereço para correspondência}

cristinaborsoi@uol.com.br 